\section{Should a Process be Developed to Recognize "Pharmacy Practice Residency Equivalency" for Pharmacists with Substantial Clinical Experience Who Have Not Completed a Pharmacy Practice Residency?}

\section{THE "PRO" SIDE}

If you're reading this debate, we suspect that you have a vested interest in a process for "pharmacy practice residency equivalency", if one exists or could be made available. ${ }^{1}$ If you are a residency graduate, you know the countless hours you toiled at reduced salary to get the Accredited Canadian Pharmacy Residency (ACPR) credential that you write so proudly after your name. And maybe, just maybe, you're wondering whose wacky idea it is to give practising pharmacists your treasured ACPR credential through an alternative (possibly less arduous) process. Conversely, if you are a practising pharmacist, you believe that your years of providing care and serving as a preceptor for pharmacy students and residents have honed your practice competencies to levels exceeding those of new residency graduates. Why then, if you have the same competencies as residency graduates, are you not entitled to those 4 extra letters after your name plus, where available, the associated academic allowance or higher step on the pay scale and preferential access to selected positions? Or perhaps you're a manager who knows about the paucity of pharmacist candidates with the knowledge and skills to be productive members of the direct patient care team upon initial hiring. At the same time, you're frustrated that some of your current high-performing pharmacists can't claim a credential that speaks volumes about the learned capabilities they bring to patient care in your facility every day. Finally, those of you who are CSHP members will know that the profession aims, by 2015 , to have all new pharmacists entering hospital or related practice complete a residency accredited by the Canadian Hospital Pharmacy Residency Board (CHPRB). ${ }^{2}$ A goal focused exclusively on new pharmacists entering practice is well meaning but overlooks the bigger picture. What about all those other pharmacists being left behind-again - the ones who've been advancing patient care for years, despite Y2K, SARS, H1N1, back orders of epic proportions, and incessant staffing shortfalls? After all, everyone knows that residencies have operated essentially the same way for over 50 years, according to a very resourceintensive training model. Hoping to find funding and capacity to train exponentially more new residents using that same method before 2020, let alone 2015, is a long shot at best. ${ }^{3}$
We've obviously overstated these imagined points of view for effect. But we couldn't have imagined them if we hadn't heard one or more versions of them at some point in our careers. For the record, each of us has completed at least one residency, yet we are not among the members of the pharmacy community who take a negative stance toward recognizing acquisition of pharmacy residency competencies by means other than a 1-year pharmacy residency program. We have taken the "pro" position in this "Point Counterpoint" not because we yearn for chaos in the well-established order of things, nor because it's the easier side of the debate. We take the "pro" position because it is just plain wrong to deny pharmacists recognition for their knowledge and skills, however they have been acquired. Requiring practising pharmacists to complete a formal residency program, rather than recognizing the competencies they have acquired while practising, discounts the value of their workplace experiential learning. Experiential learning encompasses the knowledge, skills, and attitudes acquired through provision of patient care and other pharmacy services, coupled with reflection on practice. ${ }^{4}$ In expressing the "pro" point of view, we do not devalue residency training and the associated credential. Rather, our support of this position reflects the exceptionally high value that we place on the ACPR credential as objective evidence of capability to provide care-so much so that we hope to persuade you that an appropriately structured prior learning assessment and recognition process not only should but must be established in Canada, and soon!

Prior learning assessment is the summation of an individual's learning (stated as knowledge and skills) that may have been acquired through education and practice. ${ }^{5}$ The related concept of prior learning assessment and recognition is not a simple rubber stamp attesting to years of work experience. Rather, it is a systematic process by which prior learning is assessed and then recognized by granting credit toward an academic or professional certification. ${ }^{6}$ This process has allowed learners in various fields to gain credit while working, to save time and money, to increase their satisfaction and self-confidence, and to engage in continued personal development in areas of identified need. That these benefits have occurred in other sectors such as labour organizations, educational institutions, and professional associations but to only a limited extent in pharmacy (after the first professional degree) is likely an oversight rather than a deliberate act of exclusion. ${ }^{7-9}$ We suspect that most pharmacists are familiar with the extensive use of prior learning assessment and recognition to determine equivalent credit for courses in the setting of existing nontraditional PharmD programs. In a 1999 survey of nontraditional PharmD programs, ${ }^{10} 15$ (60\%) of 25 programs used prior learning assessment and recognition to 
evaluate students' requests for advanced standing for an experiential course. The most common method was portfolio assessment, which was used by 12 (48\%) of the 25 programs. Other methods included exam challenges and interviews. ${ }^{8,10}$ That CHPRB is open to prior learning assessment within residency training, with or without associated recognition, is evidenced by the inclusion of those concepts within the current residency accreditation standard. ${ }^{11}$

The ACPR credential should and could, with minimal change to the current CHPRB accreditation standard and using a prior learning assessment and recognition process acceptable to CHPRB, be conferred by a CHPRB-accredited residency program's governing body upon pharmacists who meet or exceed the requirements of the program. A systematic process to recognize "pharmacy practice residency equivalency" for pharmacists would include voluntarily evaluating, documenting, and demonstrating the equivalency of practice knowledge and skills. ${ }^{12}$

The general principles of prior learning assessment and recognition have been clearly outlined and could easily be adapted by individual residency programs. The program's learning outcomes or objectives must be clearly defined; the criteria for successful completion must be clearly defined; the learning must be assessed, verified, and documented; learning should be appropriate to subject matter and balanced between theory and practical application; and the review and awarding of credit must be performed by academic experts. ${ }^{13}$ The first criterion is the most important ${ }^{10}$ and, within the context of Canadian hospital pharmacy, the easiest to meet, as expected competencies for completion of a residency are clearly defined in the CHPRB accreditation standard. ${ }^{11}$ Furthermore, directors of accredited residency programs are already required to demonstrate that their respective programs will graduate pharmacists who are able to meet or exceed the competencies. This provides a foundation for the academic skills essential to review and award credit through prior learning assessment and recognition. ${ }^{11}$

The American College of Clinical Pharmacy recently published an article detailing the suggested steps and expected rigour of a prior learning assessment and recognition process related to pharmacy residencies. ${ }^{12}$ In that model, a curriculum vitae and an active clinical practice would be insufficient for residency equivalency. Candidates would have to submit a detailed reflective portfolio, accompanied by academic credentials from an appropriate institution, a valid pharmacist license, and proof of at least 5 years of professional experience (including direct patient care activities for a broad range of patient populations)..$^{12}$ The portfolio would document excellence in practice via multiple sources of information over time. Each item in the portfolio would be associated with a specific competency and would provide sufficient evidence to demonstrate proficiencies in various domains of pharmacy practice. Other essential components of the reflective portfolio would include a statement of self-assessment, reasons for pursuing pharmacy residency equivalency, accomplishments and activities (education, work experience, licensure, publications), supporting documents, and feedback and evaluation by qualified peers, organizations, or regulatory authorities. ${ }^{12}$ Before applying for equivalency, pharmacists employed in an organization that supports workplace experiential education could compensate for any shortfalls in knowledge or skill through one or more changes in work assignments, by undertaking projects within the workplace, through enhanced documentation of performance assessments, or via supplemental or exchange training outside the workplace.

We certainly need to ensure that new pharmacists entering practice have the knowledge and skills to provide patient care at the level required by our modern health care systems. However, we also need to invest in pharmacists who are already in practice, giving those who have met or exceeded expected residency competencies fair credit for their knowledge and skills. Establishing a nationally accepted framework of prior learning assessment and recognition for ACPR credentialling of pharmacists already in practice is, however you look at it, the right thing to do.

\section{References}

1. Murphy JE, Nappi JM, Bosso JA, Saseen JJ, Hemstreet BA, Halloran MA, et al. American College of Clinical Pharmacy's vision of the future: postgraduate pharmacy residency training as a prerequisite for direct patient care practice. Pharmacotherapy 2006;26(5):722-733.

2. CSHP 2015-a practice excellence initiative for pharmacists in hospitals and related healthcare settings. Ottawa $(\mathrm{ON})$ : Canadian Society of Hospital Pharmacists; 2007 [cited 2010 Jul 27]. Available from: www.cshp.ca/ programs/cshp2015/index_e.asp

3. Impact of increased experiential training on hospital pharmacy practice 2006. Ottawa (ON): Canadian Society of Hospital Pharmacists: 2006 [cited 2010 Jul 27]. Available from: www.cshp.ca/dms/dmsView/ 2_1_Experiential-Training-Letter-Final.pdf (membership required to access content).

4. Schon DA. The reflective practitioner: how professionals think in action. New York (NY): Basic Books; 1983.

5. Peruniak G, Welch D. The twinning of potential: toward an integration of prior learning assessment with career development. Can J Couns 2000;34(3):232-245.

6. Morrissey M, Myers D, Belanger P, Robitaille M, Davidson P, Van Kleef $\mathrm{J}$, et al. Achieving our potential: an action plan for prior learning assessment and recognition (PLAR) in Canada. Halifax (NS): PLA Centre; 2008

7. Aarts S, Blower D, Burke R, Conlin E, Howell B, Howerth CE, et al. A slice of the iceberg: cross-Canada study on prior learning assessment and recognition. Ottawa $(\mathrm{ON})$ : Canadian Association for Prior Learning Assessment; 1999.

8. Aarts S, Blower D, Burke R, Conlin E, Lamarre G, McCrossan W, et al. Feedback from cross-Canada study of prior learning assessment and recognition. Ottawa (ON): Canadian Association for Prior Learning Assessment; 2003.

9. Recognition for learning: about PLAR. Toronto (ON): Canadian Association for Prior Learning Assessment: [cited 2010 Jul 27]. Available from: http://recognitionforlearning.ca/practitioner/aboutPLAR.php

10. Fjortoft NF, Zgarrick DP. Survey of prior learning assessment practices in pharmacy education. Am J Pharm Educ 2001;65(1):44-53.

11. Canadian Society of Hospital Pharmacists, Canadian Hospital Pharmacy Residency Board. Accreditation standards: January 2010. Ottawa (ON): Canadian Society of Hospital Pharmacists; 2009 [cited 2010 Jul 27]. Available from: www.cshp.ca/programs/residencyTraining/CHPRB_ Standards_2010_-_FINAL.pdf

12. American College of Clinical Pharmacy; Jordan CJ, Wall GC, Lobo B, Wilkinson J, Creekmore FM, Sorrells K, et al. Postgraduate year one pharmacy residency program equivalency [commentary]. Pharmacotherapy 2009;29(12):399e-407e. Also available from: www.accp.com/docs/ positions/commentaries/Jordan_PGY1.pdf 
13. Whitaker U. Assessing learning: standards, principles and procedures. Philidelphia (PA): Council for Adult and Experiential Learning; 1989.

Donna M M Woloschuk, PharmD, MDE, ACPR, FCSHP

Regional Pharmacy Manager, Educational Services

Colette B Raymond, PharmD, MSC, ACPR

Staff Development and Practice Evaluation Pharmacist

Winnipeg Regional Health Authority

Winnipeg, Manitoba

\section{Disclaimer}

Dr Woloschuk is a former chairperson and member of the Canadian Hospital Pharmacy Residency Board. The opinions expressed herein do not represent the past or current views of the CHPRB.

\section{THE "CON" SIDE}

I admire pharmacists who, through determination, ingenuity, and commitment, have developed sophisticated practices and are themselves "clinically mature". ${ }^{1}$ I know a few and would be pleased to be a patient under their care. However, now is not the time in our profession's development to divert precious resources to the dubious enterprise of creating a residency equivalency process.

Given that we already have a generally accepted understanding of the amount of practice experience that is similar to a residency, such a process strikes me as a solution in search of a problem. In most unionized environments, for example, the Accredited Canadian Pharmacy Residency (ACPR) credential is formally recognized, opening doors to higher grade levels and more diverse job portfolios. Fortunately, so is "equivalent experience", and a residency is commonly declared equivalent to 3 or 5 years of relevant experience. Completion of a residency is not required for entry into PharmD programs, traditional or otherwise. One can even be the director or coordinator of a residency program if one has "a pharmacy practice residency or ... equivalent experience", where "equivalent experience is interpreted as three years experience in a broad range of pharmacy operational, clinical and/or administrative pharmacy practice.”2 Presumably, if we are comfortable in articulating equivalency for those running our residency programs, we can live with similar working standards for equivalency, which we already use when it comes to hiring and to determining grade levels and advancement opportunities. No new credentialling system is required.

Whatever a seasoned practitioner's motivation for seeking a residency equivalency credential, whether a better job, more clinical time, a higher hourly wage, an "advanced practitioner" certificate, or "authorized prescriber" status from a licensing body, attainment of the credential demands proof of competence. The stakeholders in each of these situations must determine what it means to prove competence in their own contexts. It would be impossible to build a residency equivalency system that could cover all of the competencies to which it might aspire. If a licensing body makes the mistake of not recognizing equivalent experience or does not provide an opportunity to prove relevant competency, it should correct the oversight. Pharmacists taking it upon themselves to build a new credentialling system simply to circumvent such mistakes are following an unproductive path.

In fact, creating a system to grant credentials to people who are already practising at a high level is precisely where we should not be directing scarce resources in these times of rapid change, expansion of roles, aspirations to pharmacist prescribing, medication management, and Blueprint for Pharmacy dreams. Those resources should be devoted to developing less skilled pharmacists to meet these challenges. Thankfully, we already have systems for doing this: residency programs (full-time or part-time), PharmD programs (full-time or part-time, entry-level or post-baccalaureate), board certification, and pharmacy departments' own staff development programs. We need the creation of more such programs and the expansion of existing ones. ${ }^{3,4}$ It is into these programs that we should be pouring resources. Credentialling existing competent practitioners is likely to compete directly with these more important priorities.

The onus to identify ways in which a residency equivalency process could enhance patient care or our profession lies with its proponents. The task of justifying the resource commitment needed to carry it out intensifies that challenge.

Proponents might argue that more opportunities are needed for pharmacists to develop their clinical skills. I enthusiastically agree. However, a process to grant residency equivalency would benefit mainly pharmacists who already have advanced practices. Methods to liberate pharmacists from the dispensary or to develop their clinical skills constitute an entirely different (and more important) topic.

Others might assert, as the American College of Clinical Pharmacy has done, ${ }^{5}$ that because pharmacy residency training should be a prerequisite for pharmacists engaged in direct patient care, temporary residency equivalency programs are a necessity. This, of course, is circular logic. The American College of Clinical Pharmacy could as easily exempt, say, those with 7 years of relevant practice experience or graduates from 1990 or earlier. Aspirational goal statements do not compel the creation of makeshift credential equivalency programs that are either of dubious import (if administered leniently) or inordinately resource-intensive (if done rigorously). Notably, the 2015 goals and objectives of the Canadian Society of Hospital Pharmacists ${ }^{6}$ and the American Society of Health-System Pharmacists ${ }^{7}$ do not self-impose the requirement that all direct patient care pharmacists have residency training, aspiring only that $100 \%$ or $90 \%$, respectively, of new entrants to practice have the ACPR credential.

In trying to imagine a situation in which creating a residency equivalency process would be justified, I am most sympathetic to the rural hospital environment. I occasionally hear about pharmacists in this setting who wish to develop their skills but are unable, for obvious practical reasons, to relocate to a larger centre to complete a residency. To their credit, many in this situation opt for a nontraditional PharmD. This is far different from a rural practitioner believing that his or her skills are sufficiently advanced that residency equivalency recognition is needed to realize local job aspirations. To my knowledge, it is normal for a pharmacist in a rural hospital, even one who has not completed a residency, to have significant clinical responsibilities, 
to be the drug distribution supervisor, to chair the pharmacy and therapeutics committee, and to be the director of pharmacy, sometimes simultaneously. I cannot see how conferring an ACPR-like credential will help these pharmacists in their respective careers.

In larger urban hospitals, opportunities for advancement abound, as hundreds of pharmacists have proven over the years through pursuit of various programs and their own learning efforts. In this context, creating a new credentialling process would serve a small audience and would lack a convincing argument that the benefits justify the effort.

Those for whom the possible developmental aspects of residency equivalency programs hold appeal should consider that in our current age of competency-based residency training, ${ }^{2}$ persons or entities who would be responsible for granting equivalency credentials not only must attain some accreditation of their own in order to assess the competencies of applicants but also will themselves be making a major commitment to the task of assessing pharmacists' knowledge and skills. It is possible that the effort will be similar to operating a small, conventional, part-time residency program.

Consider the following thought experiment: Imagine a world in which every seasoned clinical practitioner without residency training was immediately granted the ACPR credential. What exactly would be different for them? For their patients? For their care team? For our profession? Very little, I suspect, over the short, medium, or long term, despite the cost and effort that would be needed to bring this imagined world into existence.

Our efforts should overwhelmingly be aimed at developing the skills of our existing practitioners and creating new opportunities for pharmacists with high potential to enter and advance in the patient care realm. This primarily means expan- sion of clinical training opportunities of all types, not diversion of effort to credentialling systems for the already-accomplished.

If you want the ACPR credential, do a residency.

References

1. Ray MD. Clinical maturity in pharmacy. Pharmacotherapy 2006;26(5):594-596.

2. Canadian Society of Hospital Pharmacists, Canadian Hospital Pharmacy Residency Board. Accreditation standards: January 2010. Ottawa (ON): Canadian Society of Hospital Pharmacists; 2009.

3. Blueprint for Pharmacy — designing the future together. Ottawa $(\mathrm{ON})$ : Canadian Pharmacists Association; [cited 2010 Sep 2]. Available from: www.pharmacists.ca/content/about_cpha/whats_happening/cpha_in_ action/publications.cfm

4. American College of Clinical Pharmacy; Jordan CJ, Wall GC, Lobo B, Wilkinson J, Creekmore FM, Sorrells K, et al. Postgraduate year one pharmacy residency program equivalency [commentary]. Pharmacotherapy 2009;29(12):399e-407e. Also available from: www.accp.com/docs/ positions/commentaries/Jordan_PGY1.pdf

5. American College of Clinical Pharmacy. Postgraduate year one pharmacy residency program equivalency [position statement]. Pharmacotherapy 2009;29(12):1493-1494.

6. CSHP 2015- a practice excellence initiative for pharmacists in hospitals and related healthcare settings. Ottawa $(\mathrm{ON})$ : Canadian Society of Hospital Pharmacists; 2007 [cited 2010 Sep 2]. Available from: www.cshp.ca/programs/cshp2015/index_e.asp

7. 2015 initiative. Bethesda (MD): American Society of Health-System Pharmacists; 2010 [cited 2010 Sep 2]. Available from: www.ashp.org/ 2015

Peter Loewen, BSC(Pharm), PharmD

Vancouver Coastal Health and Providence Health Care,

part of Lower Mainland Pharmacy Services

University of British Columbia

Vancouver, British Columbia

\begin{tabular}{lll}
\multicolumn{4}{c}{ Advertisers } & IndeX \\
\hline & Ad Page & Prescribing Information \\
\hline Pharmaceutical Partners of Canada / Corporate & IFC & - \\
\hline Pharmaceutical Partners of Canada / Corporate & OBC & - \\
\hline Sandoz / Corporate & 406 & - \\
\hline
\end{tabular}

